Ebbs, P. J., and Pasquire, C. L, (2018). "Make Ready Planning Using Flow Walks: A New Approach to Collaboratively Identifying Project Constraints." In: Proc. $26^{\text {th }}$ Annual Conference of the International. Group for Lean Construction (IGLC), González, V.A. (ed.), Chennai, India, pp. 734-743. DOI: doi.org/10.24928/2018/0448. Available at: www.iglc.net.

\title{
MAKE READY PLANNING USING FLOW WALKS: A NEW APPROACH TO COLLABORATIVELY IDENTIFYING PROJECT CONSTRAINTS
}

\author{
Paul J. Ebbs ${ }^{1}$ and Christine L. Pasquire ${ }^{2}$
}

\begin{abstract}
Many authors identify flow and pull as key lean production principles. In lean construction (LC)these principles are embodied within the "Last Planner® System" (LPS) to create more reliable workflow which is the heart of Lean Project Delivery. LPS has continued to evolve and develop over the last 25 years with pull planning - identifying what tasks SHOULD be done - the last major elementadded. However, "pull planning" is often misunderstood as the entirety of LPS and frequently referred to as "Last Planner". The remaining levels of the Last Planner "System" - CAN; WILL; DID and LEARN are not being used as originally intended by LPS developers Ballard and Howell. The struggle often begins with Make Ready Planning (CAN).

This paper is the first output of a two-year research project focused on implementing the CAN; WILL; DID; LEARN levels of LPS within organisation (X). It outlines how the 8 Flows of Lean Project Delivery andthe "Flow Walk" are being used as a structured approach to collaboratively identify constraints and incorporate them into the risk registers and Make Ready Planning. This approach was effective to identify constraints and also create a shared understanding of project scope within project teams.
\end{abstract}

\section{KEYWORDS}

Last Planner System,Make Ready, Flow Walks, Constraints, Risk Management

\section{INTRODUCTION\& BACKGROUND}

Koskela (2000) proposed the Transformation, Flow, Value (TFV) theory of construction production and stressed it should be seen from these perspectives, rather than simply the conversion of raw materials to a product. However, project teams are typicallyonly focused on maximising local productivities (optimising the piece), for example using

\footnotetext{
1 Research Fellow, Centre for Lean Projects, NTU - Nottingham Trent University, UK, +353 85804 9623,paul.ebbs@ntu.ac.uk

2 Professor of Lean Project Management, Centre for Lean Projects, NTU - Nottingham Trent University, christine.pasquire@ntu.ac.uk
} 
Work Breakdown Structures (WBS) (Ebbs, 2015; Ballard et al., 2012) rather than optimising the whole through work structuring.Sarhan et al. (2017)also recognised this narrow perspective within the safeguarding activities of procurement systems.Discrete contracts do not typically consider the interaction and interdependence between project stakeholders promoting the management of projects by enacting contracts in silos where performance is measured in isolation from whole project purpose and value. Individual interests prevail in an attempt to minimize the risk of one stakeholder versus another (Howell \& Koskela, 2000; Macomber \& Howell, 2003; Slivon et al., 2010). A prevailing belief is that this optimisation of individual pieces of the project through the management of discrete contracts creates resource efficiencyand that this optimisation is achieved through the elimination of waste.Some, such as Cooke and Williams (2009) even propose lean construction simply as the elimination of waste from the production cycle. However, this belief set is a flawed understanding of lean principles representing a reductionist view heavily criticised by Green (1999). The extent of this belief set was tested by Ebbs et al. (2015) as follows:

Table 1: Understanding of Lean Construction through thematic analysis $(n=84)$

\begin{tabular}{lccccccc}
\hline Code & $\begin{array}{c}\text { Total } \\
(\mathbf{8 4})\end{array}$ & $\begin{array}{c}\text { Arch } \\
(\mathbf{1 2})\end{array}$ & $\begin{array}{c}\text { Eng } \\
\mathbf{( 5 )}\end{array}$ & $\begin{array}{c}\text { Con } \\
\mathbf{( 1 8 )}\end{array}$ & $\begin{array}{c}\text { QS } \\
\mathbf{( 1 0 )}\end{array}$ & $\begin{array}{c}\text { Ac } \\
\mathbf{( 3 8 )}\end{array}$ & $\begin{array}{c}\text { Owner } \\
(\mathbf{1})\end{array}$ \\
\hline Reduce waste & $\mathbf{4 0}$ & 4 & 2 & 9 & 6 & 19 & - \\
Holistic process & $\mathbf{2 2}$ & 4 & 2 & 5 & 4 & 7 & - \\
Reduce material waste & $\mathbf{1 7}$ & - & - & 2 & 3 & 11 & 1 \\
Reduce time & $\mathbf{1 6}$ & - & - & 4 & 1 & 11 & - \\
Reduce labour/resources & $\mathbf{1 5}$ & 1 & - & - & 5 & 9 & - \\
Reduce cost & $\mathbf{1 4}$ & 2 & 1 & 5 & - & 6 & - \\
System & $\mathbf{7}$ & - & 1 & 1 & - & 5 & - \\
Sustainability & $\mathbf{7}$ & 2 & - & 1 & 2 & 2 & - \\
Philosophy/concept & $\mathbf{6}$ & 1 & - & - & - & 5 & - \\
Continuous Improvement & $\mathbf{5}$ & 2 & 1 & 2 & - & - & - \\
Quality & $\mathbf{4}$ & - & - & 1 & - & 3 & - \\
Value engineering & $\mathbf{4}$ & - & - & 2 & 2 & - & - \\
\hline Flow & $\mathbf{2}$ & - & $\mathbf{1}$ & - & - & $\mathbf{1}$ & - \\
\hline Culture & $\mathbf{2}$ & - & - & 1 & - & 1 & - \\
Safety & $\mathbf{1}$ & - & - & - & - & 1 & - \\
\hline
\end{tabular}

Key: Arch - architect; Eng - engineer; Con - contractor; QS - quantity surveyor; Ac academic; Owner - owner/client

This finding correlates somewhat with the reductionist perspective and indicates a minimal consideration of flow or value. This is interesting as both Womack et al.'s (1990)5 Lean principles and Liker's (2004) 14 Toyota Way Management Principles are leading texts informing industry and academia; neither offers the elimination of waste as a method for efficiency but rather discuss waste reduction as an outcome of achieving flow. Eliminating waste to maximising resource efficiency is often a focus of lean literature, however helping materials, information, people and product flow is the critical 
concept to grasp (Koskela, 2014; Rother, 2010; Bertelsen et al., 2006; Modig, \& Ahlstrom, 2015; Umstot \& Fauchier, 2017; Pasquire, 2012; Pasquire \& Court, 2013; Pasquire \& Ebbs, 2017). Simply striving to eliminate waste will not necessarily create value as eliminating waste from one task may increase it in another. Therefore, it is important to optimise the whole not the individual pieces. In other words, flow efficiency beats resource efficiency because the consequence of stopping the flow of work is far greater than having spare resource capacity (slack) on hand. Workflow is stopped or interrupted by constraints some of which have a bigger impact on a project's production system.

Within a project the various team members act as "customers" and "suppliers", constantly passing information to each other through conversations. However, information flow becomes difficult without explicit shared understanding of each other's requirements and constraints (Pasquire \& Ebbs, 2017). Often, rework is required because the information is misunderstood, incomplete or incorrect. This stops the flow of work. Having shared and common understanding of the next customer's requirements (which includes constraints) is critical to improving flow (Pasquire, 2012) because often these constraints are already known by a member of the project team.

The first part of effective problem solving is to clearly identify the problem. Similarly, before removing a constraint or mitigating a risk, it must be identified. This drives appropriate action in the make ready process to prepare for flow.

The following pages introduce a new approach to collaboratively identify constraints and risk from both project first thinking and different stakeholders' perspectives. Called a "Flow Walk" it was developed within the framework of the Last Planner ${ }^{\circledR}$ System to influence desired action and to support project planning at Milestone, Phase and Make Ready Planning levels of the LPS in order to improve the reliability of schedules (Pasquire \& Ebbs 2017). The Flow Walk improves the safety and quality of assignments by replicating the effective conversations that take place during pull planning. Customers and suppliers share their understanding and conditions of satisfaction related to constraint removal and risk mitigation. The research methodology used in its development, how it has been used in practice along with some preliminary results and opportunities for future research are discussed in the following sections.

\section{RESEARCH METHODOLOGY}

The Flow Walk was designed, developed, and tested through six action research cycles within a 27 month, funded UK case study within an Organisation (X) and through external workshops at the NTU Centre for Lean Projects $2^{\text {nd }}$ Annual Research Showcase Day and LCI UK's Annual Summit in 2017. Each of the six action research cycles of the Flow Walk informed the development of the next.

\section{FLOW WALK DEVELOPMENT IN PRACTICE: ACTION RESEARCH}

The purpose of designing and developing the Flow Walk was primarily to provide a structured and collaborative approach to firstly identify project constraints at milestone level planning and secondly, to provide the context for desirable action to remove constraints within the framework of the Last Planner® System at Milestone, Phase and 
Make Ready Planning. We define a constraint as anything that would stop or disrupt the flow of project delivery in an organisation or on a project. A risk on the other hand may not transpire but could impact the production system if environmental conditions change.

Six workshops were conducted over 16 months. They combined divergent and convergent thinking to encourage essential conversations between the team and create a shared understanding of constraints and project scope. The workshops happened in this order: 1) Organisational constraint identification (June 2016) ${ }^{3}$.2) NTU Research Showcase Day to refine the process steps with industry practitioners and academics (February 2017). 3) Project constraint identification on a new $\$ 5$ million concrete raft with in-house project staff from Organisation X (June 2017) followed by 4) same project but with the preferred construction partner only (June 2017). ${ }^{4}$ 5) A $\$ 50$ million demolition and land remediation project with staff from Organisation X during scope definition, strategy outline, feasibility and pre-risk register stage (September 2017). 6) LCI UK Summit Training Day Workshop using a sample "build this room" project to share the updated process and incorporate learning from the previous action research cycles (October 2017).

\section{FLOW WALK PRE-WORK: DIVERGENT THINKING}

To gain a holistic understanding of constraints to project delivery, the first step was to solicit individual perspectives of constraints to each of the 8 Flows by simple questioning and discussion. During Flow Walk \#1 we identified the constraints through a mini brainstorming workshop $(n=3)$ using a dedicated flip chart and coloured Post-it ${ }^{5}$ for each flow. While many constraints were identified they were only from three perspectives (one of those being the embedded researcher). In order to collect more perspectives, a broader group of people were provided with an excel spreadsheet in advance of the $3^{\text {rd }}$, $4^{\text {th }}$, and $5^{\text {th }}$ Flow Walk workshops within Organisation X. Consequently, over 200 individual constraints were identified from an average of seven people at each of the Flow Walk workshops. Figure 1 is a compressed example of the A3 excel sheet used to gather the data from participants using the colours of the 8 Flow conceptual model documented by Pasquire and Ebbs (2017). ${ }^{6}$

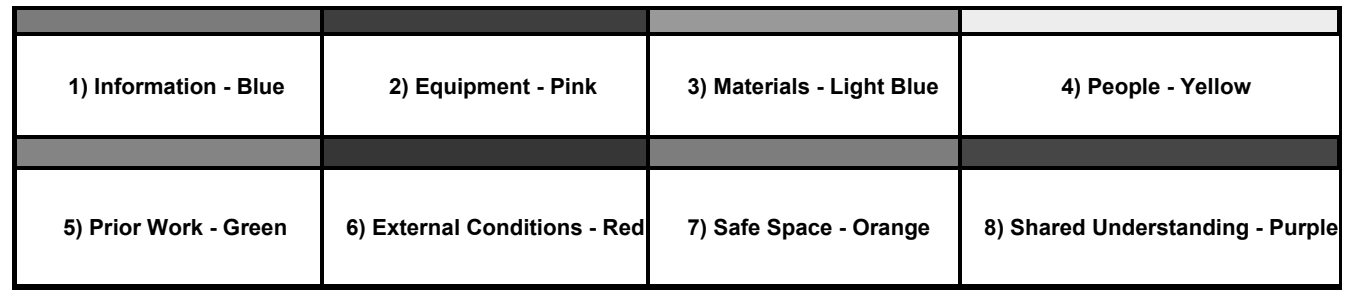

Figure 1: Sample Flow Walk Pre-Work Sheet

Pasquire and Ebbs (2017) documented the output from this workshop in IGLC 25 proceedings.

Separate workshops were held because the contractor was not in contract.

We refer to Post-its as tags in this paper also.

Flow Walks \#2 and \#6 (Research Showcase Workshops) were unable to use pre-work. Instead we had the participants write their constraints to the sample project directly onto a tag and place on the flip charts at each of the 8 Flow stations. 
The individual constraints collected in advance were transferred from the A3 prework sheets onto Post-its and then onto their respective flow sheet by the researcher ready for further development(see the flip charts in Figure $2 \& 3$ ). Similar constraints in each flow were grouped together by the researcher and assigned a category name ${ }^{7}$. The purpose of the researcher doing this was to ensure the workshop was focused and structured from the start and to keep the teams engaged during the developmental experimentation.

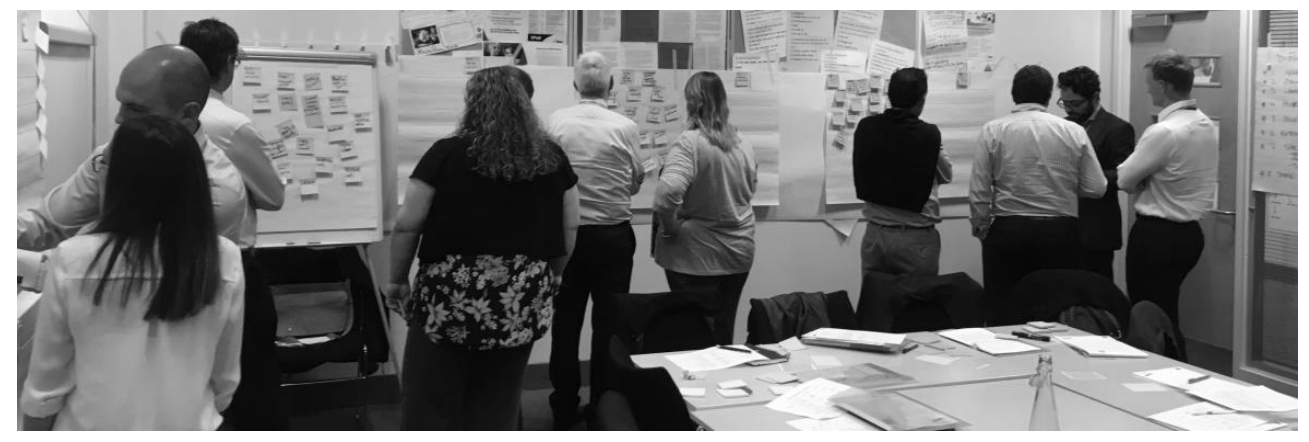

Figure 2: Flow Walk Participants at LCI UK Summit 2017

\section{FLOW WALK ROUNDS: DIVERGENT TO CONVERGENT THINKING}

In rounds 1 through 5 of the Flow Walk the participants addressed each of the bullet points listed below in order to move from divergent to convergent thinking. Conversations on the constraints in both a structured way and also from different stakeholder perspectives leveraged the participants' experience. Figure 3 illustrates the output of rounds $1,2 \& 3$ from the $6^{\text {th }}$ Flow Walk.

\section{Round 1: Individual Flow Walk - Validation}

- Validate categories (these were originally chosen by the researcher).

- Identify any constraints that impact other flows.

- Identify each multiple impacting constraint with a yellow dot and write the reference number of the impacted flow(s) on it (1 through 8).

- Turn the tag of any constraint that is either unclear/vague or requires clarification into a diamond shape.

\section{Round 2: Group Flow Walk - Consensus}

- Clarify all constraints on diamond shape tags.

- Agree on category content \& name.

- Add any additional constraints (extra tags).

\footnotetext{
${ }^{7}$ Similar constraint categories were found in multiple flows. We will discuss this more later.
} 


\section{Round 3: Individual Flow Walk - Prioritise\& Total Categories}

- Each participant has 16 red dots to place on the constraint(s) they perceive to have the biggest Level of Impact (LOI) i.e. place 2 red dots on any two tags for each flipchart (flow) but you are also allowed to place both red dots on a single tag.

- Total the categories in each flow by adding the \#tags +\#red dots + \#additional flows (numbers inside the yellow dots in Figure 3) on each line.

The diamonds in Figure 3 represent the constraint category name within each particular flow. The numbers on each category relate to the output from Round 3 which totalled the number of references to each category i.e. \#tags + \#red dots + \#yellow dots. The yellow dots relate to where the participants' perceived the constraint impacted another flow. For example: \#4 impacts the people flow and \#8 impacts the flow of shared understanding. The numbers on the diamond tags are meaningless per se. However, they helped trigger conversations to gain an understanding of different or opposing concerns between the participants. This resulted in some constraints being removed at the wall during the conversations. Furthermore, participants agreed that a reciprocal understanding of project scope and strategy began to emerge.

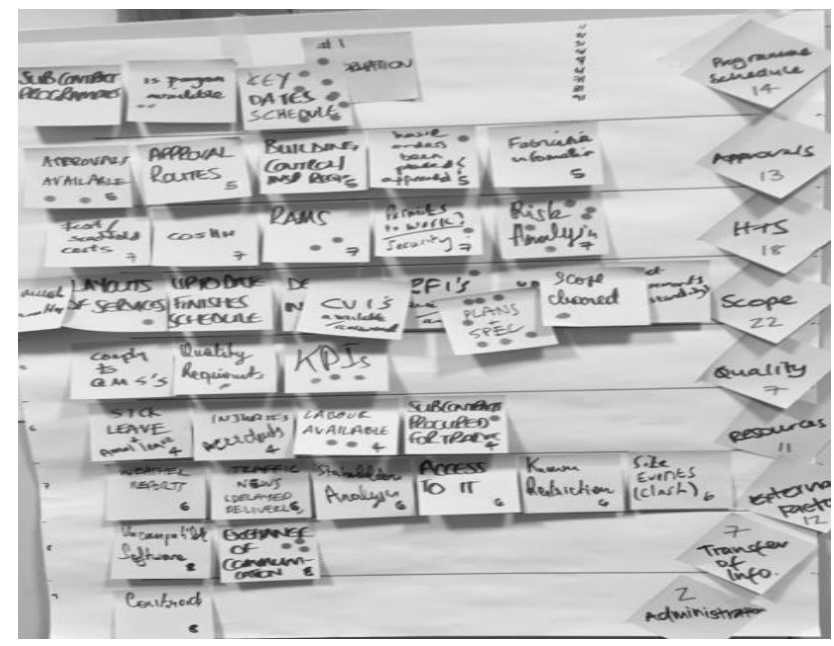

Figure 1: Flow of information output from LCI UK Summit Training Day 2017

\section{Round 4: Group Flow Walk - Combine}

- Ask the participants to remove the diamond tags from each flow and bring them to a fresh sheet of plotter paper on the wall. Place the constraint category tag with highest LOI to left hand side $(\mathrm{L} / \mathrm{H} / \mathrm{S})$ of the plotter paper.

- Add similar tags from other flows and name the new group category by consensus.

- Repeat the process until all thediamond summary tags are removed from the flip charts (flows)and are placed within their new group categories on the plotter paper.

- Total each new group of diamond tags.

- List out new group categories in order of LOI (Green ink in Figure 4\&Table 2). 


\section{Round 5: Poll Time - Level of Confidence}

The final round of the Flow Walk workshop requires the participants to individually rank each group category between 0 and 10 regarding the team's Level of Confidence (LOC) in their ability to remove the constraint where 0 is outside team's control and 10 is fully within the team's control. However, the perceived LOC for each constraint category illustrated on the $\mathrm{L} / \mathrm{H} / \mathrm{S}$ of Table 2 was identified from group rather than individual perspectives and sufficient time for discussion was not allowed.

Individual ranking of constraints was solicited from the participants during the $5^{\text {th }}$ Flow Walk because the collaborative output was being used to develop a project risk register. During Round 5 the participants are asked to:

- Total the individual responses and record the range and the average response to each group. For example, from 3 to 9 with an average of 7.8.

- Insert the LOC rating in the orange triangle beside each group category (Figure 4 $\&$ Table 2).

- Discuss the lowest and highest individual ratings and any differences of opinion.

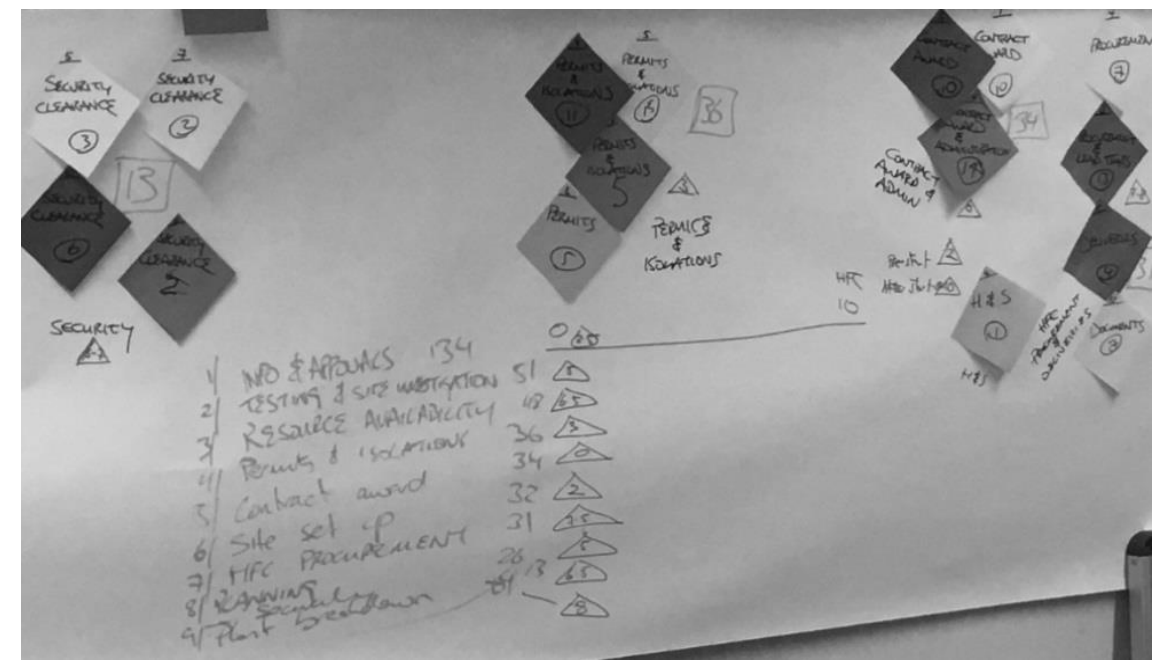

Figure 2: Output from Flow Walk \#4 with Organisation X's Construction Partner

Figure 4 illustrates the combined results of Rounds 4 and 5.The output after Round 5 is the result of convergent thinking. The diamonds in each group category illustrates how similar constraint categories appeared in \& are perceived to affect other flows. The output of Flow Walk \#4 is illustrated in the Contractor Constraint Categories section of Table 2.

The outputs from Round 5 of Flow Walks \#3 \& \#4 were combined by the researcher. Table 2 illustrates the summary of these results. Similar group categories emerged regarding communication, information, understanding, approvals, contractor equipment, site access, material procurement, and contractor resources. These categories are denoted by a tick $(\sqrt{ })$ to the $\mathrm{L} / \mathrm{H} / \mathrm{S}$ of the LOI column. Table 2 illustrates how Organisation $\mathrm{X}$ identified 7 additional constraint categories and the contractor added a further 4 categories not previously identified by their respective peers. 
Table 1: Flow Walk Group Categories of Constraints

\begin{tabular}{|c|c|c|c|c|c|c|c|c|c|c|}
\hline Rank & LOC & Organisation X Constraint Categories & & LOI & 12 & 23 & 45 & & 6 & 78 \\
\hline 1 & 10 & Communication \& Information Understanding & $\sqrt{ }$ & 66 & $\mathbf{X}$ & & $\mathrm{x} x$ & $\mathbf{x}$ & $\mathbf{X}$ & $\mathbf{X X}$ \\
\hline 2 & 10 & Approvals \& Signatures & $\sqrt{ }$ & 56 & $x \times$ & & $\mathrm{x} \mathbf{x}$ & $\mathbf{x}$ & $\mathbf{x}$ & \\
\hline 3 & 6 to 9 & Documentation & & 53 & $\mathbf{x}$ & & $x \mathbf{x}$ & $\mathbf{x}$ & $\mathbf{x}$ & \\
\hline 4 & 2 & Phase 2 & & 45 & & & $x \mathbf{x}$ & $x$ & $x$ & $\mathbf{x}$ \\
\hline 5 & 7 & Availability of Owner reps & & 37 & & & $x \mathbf{x}$ & $\mathbf{X}$ & & $\mathbf{x}$ \\
\hline 6 & 5 & Contractor equipment & $\checkmark$ & 23 & & $\mathbf{X}$ & & $\mathbf{x}$ & & \\
\hline 7 & 10 & Owner equipment considerations & & 21 & & $\mathbf{X}$ & X & $\mathbf{x}$ & & \\
\hline 8 & 10 & Material specs & & 19 & $\mathbf{X}$ & $\mathbf{x}$ & & & & \\
\hline 9 & 5 & Site access \& interface & $\sqrt{ }$ & 19 & & $\mathbf{x}$ & & $\mathbf{x}$ & & $\mathbf{x}$ \\
\hline 10 & 8 & Planning Permission, Conditions \& Approvals & & 19 & $\mathbf{X}$ & & & $\mathbf{x}$ & $\mathbf{x}$ & \\
\hline 11 & 3 to 5 & Material procurement & $\checkmark$ & 19 & & & $x$ & & X & $\mathrm{X}$ \\
\hline 12 & 0 & Unforeseen & $\sqrt{ }$ & 17 & & $\mathbf{X}$ & & X & $\mathbf{x}$ & $\mathbf{X} \mathbf{x}$ \\
\hline 13 & 10 & Unclear or changing scope & & 14 & $\mathbf{x}$ & & & $\mathbf{x}$ & $\mathbf{x}$ & \\
\hline 14 & 5 & Contractor resource & $\sqrt{ }$ & 8 & & & $\mathrm{x} \times$ & $\mathrm{x}$ & $x$ & \\
\hline Rank & LOC & $\begin{array}{r}\text { Contractor Constraint Categories } \\
\end{array}$ & & LOI & 12 & 23 & 45 & 5 & & \\
\hline 1 & 2.5 & Information \& Approvals & $\sqrt{ }$ & 136 & $\mathbf{X X}$ & $\mathbf{X X}$ & $x \times$ & $\mathbf{x}$ & & $\mathbf{X X}$ \\
\hline 2 & 5 & Testing \& Site Investigation & & 52 & $\mathbf{X}$ & & $x \times$ & $x$ & $\mathbf{x}$ & \\
\hline 3 & 6.5 & Contractor Resource Availability & $\sqrt{ }$ & 52 & $x \times$ & $x \times$ & $x$ & & & $\mathbf{x}$ \\
\hline 4 & 3 & Permits \& Isolations & & 36 & $\mathbf{x}$ & & $x \times$ & $x$ & $x$ & \\
\hline 5 & 0 & Contract Award \& Admin & & 34 & $\mathbf{X}$ & & $x \times$ & & $x$ & $\mathrm{x}$ \\
\hline 6 & 2 & Site Set-up \& Access & $\sqrt{ }$ & 32 & $x \times$ & $\mathbf{x} x$ & & $\mathbf{x}$ & $\mathbf{x}$ & $\mathbf{x} x$ \\
\hline 7 & 5 & Planning, Problem Solving, Collaboration \& Understanding & $\sqrt{ }$ & 27 & $\mathbf{x}$ & & $\mathrm{x}$ & $\mathbf{x}$ & & $\mathrm{X} \mathbf{x}$ \\
\hline 8 & 7.5 & Contractor Procurement \& Deliveries & $\sqrt{ }$ & 24 & $\mathbf{X}$ & $\mathbf{X}$ & $x$ & & $x$ & \\
\hline 9 & 6.5 & Security Clearance & & 13 & $\mathbf{X}$ & & $x \times$ & & & \\
\hline 10 & 3 & Weather \& Unforeseen Events & $\sqrt{ }$ & 12 & $\mathbf{x}$ & $\mathbf{x} x$ & $\mathrm{x}$ & & $\mathbf{x}$ & \\
\hline
\end{tabular}

\section{FINDINGS}

During the $3{ }^{\text {rd }}$ Flow Walk workshop, pipe saddles were identified as a major constraint. However, the saddles were only identified by one safety representative during the prework. During the workshop the PM and team quickly recognised the impact. The procurement, manufacture, delivery, and installation of the bespoke saddles would have prevented the operation of the raft (its original purpose) once the construction phase was completed. The cost of the saddles was circa $\$ 65,000$. However, many suspected the time delay to operations would have been several months. Evidence subsequently emerged how constraints are contingent on project purpose. It turned out the saddles were no longer required as the original purpose (use) of the raft changed after $25 \%$ of the raft was poured because of a business change within Organisation X's Parent Organisation. While unclear or changing scope (purpose) was identified as a major risk during Flow Walk \#3 by Organisation $X$ and this was recognised in Table 2 as being fully within the control of the team, it turned out that those with intimate knowledge of this possibility were not involved in the Flow Walk pre-work or workshop. As a result, the risk was not specifically identified. However, specialised and expensive modifications to equipment required to operate the raft were identified as significant constraints in the Flow Walk, but this equipment became redundant as a result of the change in project purpose.

During Flow Walk \#4, breakdown of the concrete batching plant was identified as a risk that would disrupt the flow of the project. However, this was only identified by the contractor's planner and the risk to the project delivery schedule was not deemed significant. The risk became a reality and project production stopped for 2 days due to the concrete plant breakdown from cold weather (external conditions) and equipment failure. Furthermore, while slack and set-based thinking were suggested by NTU so spare capacity was available (i.e. another plant), single source procurement was preferred to 
maximise resource efficiency. The primary purpose of the $5^{\text {th }}$ Flow Walk was to develop a risk register. The participants' found that this approach probably doubled the number of risks identified over a traditional risk workshop principally because the traditional approach lacks the depth of collaborative engagement $\&$ therefore range of knowledge and expertise.

\section{CONCLUSION}

The LPS has added "CAN" and "WILL" to traditional planning. "CAN" through the make ready process to screen tasks for constraints and "WILL" through commitment planning and control, but, reliable commitments are only possible if effective make ready planning has occurred. Consequently, the LPS is only truly effective when used in its entirety(Ballard, \& Tommelein, 2016; Koskela, \& Howell, 2002). During the case study it was observed the struggle with LPS began with make ready supporting previous observations that pull planning or just tags on a wall are often described as "Last Planner"(Daniel, 2017).While pull planning is helpful to identify sequence, dependencies and constraints and is a pre-requisite to the make ready process, the success of make ready is ultimately never known until the person waiting for the work declares their satisfaction. In the case of the saddles or the availability of concrete this would not have been known for 6 - 9 months. The impact of the saddles and equipment modifications on the project was a significant amount of unnecessary work and overburden to a project team - types of waste that impact flow and value creation. This example illustrates how the impact of constraints is contingent on project purpose being clear and communicated sufficiently and emphasized the importance of having the right people in the room during project definition phase (Ballard, 2008) to ensure purpose or alternative purposes (using set-based thinking) are well defined from the outset in order to plan for flow efficiency.

Additionally, risk is currently not explicitly considered during make ready planning. Risk is by definition uncertain. This may help explain why teams often struggle with make ready planning as resource efficiency is favoured because incorporating something that may not happen into the planning system is not valued (i.e. upfront cost allocation and planning for flow efficiency). We conclude that the "Flow Walk" is an effective approach to identify constraints and risks as well as creating a shared understanding of project scope, strategy and purpose. Furthermore, the success of a Flow Walk could be gauged by the examining data collected from missed commitments to understand how effectively constraints and risks were identified and removed. Future research will focus on developing the Flow Walk so that risk can be pulled into production planning. Essentially, this calls for a new approach to risk management where risk is embraced rather than passed on. A research question remains: how can teams measure something that never happens? i.e. if the constraint or risk never impacts the production system because it was made ready?

\section{REFERENCES}

Ballard, G., Kim, Y., Azari, R., \& Cho, S. (2012). Starting from Scratch: A New Project Delivery Paradigm. Construction Industry Institute Research Report. Austin, Texas.doi/pdf/10.1061/9780784413517.231 
Ballard, G. (2008). The Lean Project Delivery System: An Update. Lean Construction Journal, 2008, 1-19.

Bertelsen, S., Koskela, L., Henrich, G.,\& Rooke, J. (2006). Critical Flow - Towards a Construction Flow Theory. In: 14th Annual Conference of the International Group for Lean Construction. Santiago, Chile, 1-. pp 31-32.

Cooke, B., \& Williams, P. (2009).Construction Planning, Programming \& Control. Oxford, UK. Wiley-Blackwell

Daniel, E.I. (2017).Exploratory study into the use of Last Planner® System and collaborative planning for construction process improvement, Doctoral dissertation, Nottingham Trent University, Nottingham, UK.

Ebbs, P.J., Sexton, P., Greensmith, D.G. , Clare, B.G., Gibson, V. \& Turner, R. (2015).Lean Construction Theory and Practice: An Irish Perspective. In:, Seppänen, O., González, V.A. \&Arroyo, P., 23rd Annual Conference of the International Group for Lean Construction. Perth, Australia, 29-31 Jul 2015. 496-506

Green. S.D (1999). The Dark Side of Lean Construction: Exploitation and Ideology. $7^{\text {th }}$ Annual Conference of IGLC, Berkeley, USA

Howell, G.A.,\& Koskela, L. (2000).Reforming Project Management: The Role of Lean Construction. In:, 8th Annual Conference of the International Group for Lean Construction. Brighton, UK, 17-19 Jul 2000.

Koskela, L. (2000). An Exploration towards a Production Theory and its Application to Construction. PhD Dissertation, VTT Building Technology, Espoo, Finland. 296 pp., VTT Publications: 408, ISBN 951-38-5565-1; 951-38-5566-X.

Macomber, H. \& Howell, G.A. (2003).Linguistic Action: Contributing to the Theory of Lean Construction.In: 11th Annual Conference of the International Group for Lean Construction.Virginia, USA

Modig, N., \& Ahlstrom, P. (2015). This is Lean: Special Edition for the Lean Construction Institute. Stockholm. Sweden. Rheologica.

Pasquire, C. (2012).The 8th Flow - Common Understanding.In: I. D. Tommelein \& C. L. Pasquire,20th Annual Conference of the International Group for Lean Construction. San Diego, USA, 18-20 Jul 2012

Pasquire, C. \& Ebbs, P. (2017).Shared Understanding: The Machine Code of the Social in a Socio-Technical System.In:, 25th Annual Conference of the International Group for Lean Construction. Heraklion, Greece, 9-12 Jul 2017. 365-372.

Rother, M., (2010). Toyota Kata: Managing people for improvement, adaptability and superior results. New York, NY: McGraw-Hill.

Sarhan, S., Pasquire, C., Manu, E. \& King, A., (2017). Contractual governance as a source of institutionalised waste in construction: a review, implications, and road map for future research directions. International Journal of Managing Projects in Business, 10 (3). ISSN 1753-8378

Slivon, C.A., Howell, G.A., Koskela, L. \& Rooke, J. (2010).Social Construction: Understanding Construction in a Human Context In:, Walsh, K. \& Alves, T., 18th Annual Conference of the International Group for Lean Construction. Haifa, Israel, 2-11

Umstot, D., \& Fauchier, D. (2017). Lean Project Delivery - Building Championship Project Teams. Createspace. NY. 